Mice and RAW264.7 Cells. Frontiers in pharmacology. 2020. № 11, C. 1070. doi.org/10.3389/fphar.2020.01070.

7. Yarza R., Vela S., Solas M., Ramirez M. J. c-Jun N-terminal Kinase (JNK) Signaling as a Therapeutic Target for Alzheimer's Disease. Frontiers in Pharmacology. doi: 2016321 10.3389/fphar.2015.00321.

DOI https://doi.org/10.30525/978-9934-26-182-4-40

\title{
МОРФОЛОГИЧЕСКИЕ ИЗМЕНЕНИЯ В ЯИЧНИКАХ У ВИЧ-ИНФИЦИРОВАННЫХ ЖЕНЩИН
}

\author{
Литвиненко М. В. \\ кандидат медицинских наук, \\ доцент кафедры нормальной и патологической клинической анатомии \\ Одесский национальный медицинский университет

\section{Олейник Н. Н.} \\ кандидат медицинских наук, \\ доиент кафедры нормальной и патологической клинической анатомии \\ Одесский национальный медицинский университет \\ Кошельник Е. Л· \\ кандидат медицинских наук, \\ доиент кафедры нормальной и патологической клинической анатомии \\ Одесский национальный медицинский университет \\ м. Одесса, Украина
}

Проблема охраны репродуктивного здоровья имеет особую, не только медицинскую, но и социальную значимость [1,2]. Женская половая система (ЖПС) является самым распространенным местом заражения при передачи ВИЧ женщинам, при этом вирусное ремоделирования затрудняет клиническую и морфологическую диагностику $[3,4]$. Несмотря на свое анатомическое расположение, яичник является местом воздействия патогенов в женском репродуктивном тракте человека [5]. Имеются данные о развитии при этом дисфункции яичников. Так, нарушение функции яичников, сопровождается хронической ановуляцией в репродуктивном возрасте и периоде менопаузального перехода, что следует рассматривать как фактор риска развития заболеваний органов и других 
систем на фоне развития иммунодефицитных состояниях. Повреждение ткани яичников ведет к нарушению гормонального гомеостаза, что сопровождаются изменением дисбалансом эстрогена, прогестерона и других гормонов, что стимулирует пролиферацию эпителия, повышая риск злокачественной трансформации [8]. Увеличение продолжительности жизни ВИЧ-инфицированных женщин [8] требует проведения исследований репродуктивного здоровья данной категории пациенток. В связи с вышеизложенным целью настоящего исследования явилось выявление морфо-функциональных особенностей яичников у ВИЧ-инфицированных.

Материал и методы: Нами отобрано 30 случаев секционного материала умерших женщин с подтвержденной ВИЧ-инфекцией (исследуемая группа). В исследуемой группе ВИЧ-инфекция была верифицирована с помощью иммуноферментного анализа сыворотки (ELISA) с подтверждением вестерн-блоттингом. Число лимфоцитов CD4 $<100$ клеток / мкл считалось «низким». Возраст женщин колебался от 20 до 45 лет, в среднем 33,9 года. При наборе обеих групп был использован принцип рандомности. Материал фиксировали в 10\% нейтральном забуференном формалине, после чего заливали парафином. Из подготовленных блоков изготовлены срезы толщиной $5 \times 10^{-6}$ м. Срезы окрашивали гематоксилином и эозином. Микроскопическое исследование проводили на микроскопе «Olympus BX41» с последующим морфометрическим исследованием с помощью программы «Olympus DP-soft 3.12», с помощью которой определяли толщина эпителия, толщина белочной оболочки яичника, толщина коркового вещества яичника, толщина мозгового вещества яичника, диаметр примордиального фолликула, количество первичных фолликулов, количество вторичных фолликулов, количество третичных фолликулов, количество атретических фолликулов, относительный объем соединительной ткани. Подсчет количества исследуемых структур производился на $1 \times 10^{-4} \mathrm{~m}^{2}$ площади ткани. Все значения выражены в виде средних значений и стандартной ошибки среднего для статистического анализа [9]. Принятый уровень значимости $\mathrm{p} \leq 0,05$.

Результаты. Измерение размеров яичников выявило их размеры соответствующие $3,91 \pm 0,22 \times 2,83 \pm 0,11 \times 1,47 \pm 0,12 \mathrm{~m}^{2}$ в группе сравнения и $2,53 \pm 0,28 \times 2,04 \pm 0,18 \times 1,43 \pm 0,15$ м $^{2}$ в исследуемой группе. Масса органа

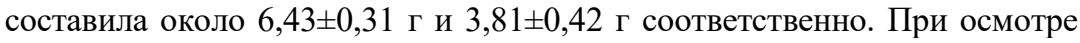
яичников обращает на себя внимание крупно бугристая поверхность органа в группе ВИЧ-инфицированных, на разрезе органа у женщин обеих групп макроскопически хорошо выделяются корковое и мозговое 
вещество, белочная оболочка утолщена в группе в группе инфицированных женщин. При гистологическом исследовании корковое вещество представлено клетками веретеновидной формы, расположенными близко друг к другу, похожими на набухшие фибробласты, и коллагеновой стромой, содержащей относительно небольшое количество клеток. В мозговом веществе представлена преимущественно рыхлая соединительная ткань. Во внутренней зоне коркового вещества выявляется наличие фолликулов среди которых выделяется примордиальные, первичные (преполостные), вторичные (полостные) и третичные, соотношение которых в исследуемых группах не одинаково. Кроме того, отмечается наличие атретических фолликулов, количество которых в группе женщин с ВИЧ значительно больше. В группе сравнения фолликулы расположены в строме коркового вещества, примордиальные локализованы по периферии, а зреющие - в более глубокой зоне. В группе женщин с выявленной ВИЧ-инфекцией отмечается истончение коркового слоя, в то время как толщина мозгового вещества существенно увеличена. В обеих группах выявляются желтые тела разной степени зрелости и белые тела, представляющие собой рубчики на месте инволюции желтых тел. В группе инфицированных женщин обращает на себя внимание существенное разрастание соединительной ткани, представленное преимущественно коллагеновыми волокнами. В сосудистом русле выявляются выраженные явления гиалиноза.

Обсуждение. Длительно персистирующая инфекция половых органов приводит к изменению рецепторов эстрадиола и прогестерона в ткани эндо- и миометрия. В соответствии с этой теорией, каждый атрофичный орган легко подвержен влиянию неспецифических раздражителей, так как является тканью со сниженной или отсутствующей функцией. Таким раздражителем выступает любой фактор, способный вызвать воспалительную реакцию, тем более что для инфекционного фактора тонкий атрофичный эндометрий - хорошая питательная среда. Длительные морфологические и функциональные изменения в ЖПС обусловливают возможность патологической афферентации в структурах центральной нервной системы, регулирующих деятельность гипоталамогипофизарно-яичниковой системы. В свою очередь нарушения в этой системе приводят к развитию вторичной гипофункции яичников, формированию ановуляции по типу абсолютной или относительной гиперэстрогении и, как следствие, гиперпластических процессов эндометрия. В данном исследовании мы не изучали количественный и качественный состав воспалительного инфильтрата, данные о котором можно использовать в качестве иммуногистохимического предиктора течения 
патологического процесса. В связи с этим данные о состоянии яичников могут использоваться как дополнительный критерий для более рационального стадирования, выявление групп риска, прогнозирования заболеваниий и определения выбора метода терапии. В частности, практическое значение имеет определение ER и PR. Эстроген- и прогестеронрецепторный статус опухоли репродуктивной системы (молочной железы, матки, яичников, маточных труб) признан одним из самых объективных прогностических маркеров. При этом в ходе нашей работе выявлены признаки ускорения инволютивных процессов яичников сопровождающихся атрофией и склерозом органа признаками чего следует рассматривать уменьшение размеров органа, его крупнобугристая поверхность, морфометрически подтвержденное уменьшение толщины эпителия и утолщение белочной оболочки. В исследуемой группе женщин наблюдается незначительное снижение количества примордиальных фолликулов, выраженное снижение количества первичных, вторичных третичных фолликулов, увеличение количества артретических фолликулов и выраженные склеротические изменения. При изучении гистологических препаратов яичников установлено, что наличие ВИЧинфицирования ведет к негативным эффектам со стороны женской репродуктивной системы с знаками угнетения репродуктивной способности. Отмечается морфофункциональная перестройка коркового и мозгового вещества яичников с истончением коркового слоя, в то время как толщина мозгового вещества существенно увеличена. В корковом веществе ярко выражена атрезия фолликулов. Атрезии чаще подвергались вторичные растущие фолликулы, реже третичные фолликулы. Патогенетические механизмы данной перестройки требуют дополнительных исследований.

Выводы. Морфо-функциональные особенности яичников у ВИЧинфицированных характеризуется ускорением инволютивных процессов с развитием выраженной атрофии и склерозом органа, что характеризуется уменьшением размеров органа, уменьшением толщины эпителия и утолщением белочной оболочки, снижением количества примордиальных, первичных, вторичных, третичных фолликулов, увеличением количества артретических фолликулов, истончением коркового слоя и выраженным разрастанием соединительной ткани.

\section{Литература:}

1. Havaei M, Saeieh SE, Salehi L. Perspectives of adolescents regarding the sexual and reproductive health self-care: a theory-based qualitative research [published online ahead of print, 2020 Jun 5]. Int J Adolesc Med Health. 
2020;/j/ijamh.ahead-of-print/ijamh-2020-0003/ijamh-2020-0003.xml. doi:10.1515/ijamh-2020-0003

2. Cavaliere G. The problem with reproductive freedom. Procreation beyond procreators' interests. Med Health Care Philos. 2020 Mar;23(1):131140. doi: 10.1007/s11019-019-09917-3. Ma T, Luo X, George AF, et al. HIV efficiently infects $\mathrm{T}$ cells from the endometrium and remodels them to promote systemic viral spread. Elife. 2020;9:e55487. Published 2020 May 26. doi:10.7554/eLife.55487

3. Haase AT. Overview of the landscape of HIV prevention. Am J Reprod Immunol. 2014 Jun;71(6):490-4. doi: 10.1111/aji.12228. Epub 2014 Apr 4. PMID: 24702688.

4. Patel MV, Shen Z, Wira CR. Poly (I:C) and LPS induce distinct immune responses by ovarian stromal fibroblasts. J Reprod Immunol. 2018;127:36-42. doi:10.1016/j.jri.2018.05.001

5. Yalamanchi S, Dobs A, Greenblatt RM. Gonadal function and reproductive health in women with human immunodeficiency virus infection. Endocrinol Metab Clin North Am. 2014;43(3):731-741. doi:10.1016/j.ecl.2014.05.002 